\title{
Childhood obesity: An epidemic in waiting?
}

0
0
0
0
0
0
$\frac{1}{4}$

\section{Ritesh Singh}

Department of Community Medicine, College of Medicine and JNM Hospital, Kalyani,

West Bengal, India

Address for the Correspondence:

Dr. Ritesh Singh,

Department of Community

Medicine, College of Medicine and JNM Hospital, Kalyani, West

Bengal, India.

E-mail: drriteshsingh@yahoo.com

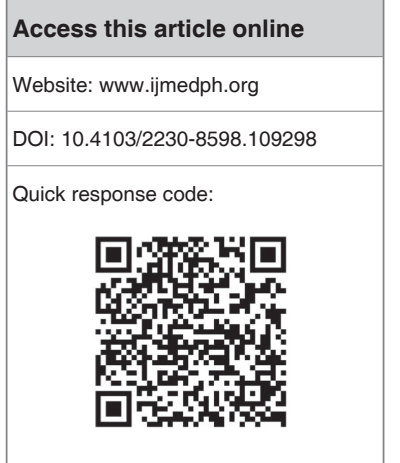

Progress of a country comes at a price. With the booming economy, Indians have now more food stuff to eat. Most of the time what we eat and give our children to eat is not healthy. Consequently, a lot more Indian children are becoming overweight like their western counterparts. Approximately 22 million children, under five years of age, are overweight across the world. The worst part is that we do not know for sure what proportion of Indian children are overweight. Different studies in India have shown a wide range of prevalence of childhood obesity. Recent studies have proved beyond doubt that this impending epidemic is not only restricted to the elite children in our country, but has crossed the socioeconomic divide and childhood obesity is on the rise even among the less privileged ones. Recent findings have shown that the propensity to become obese is evident as early as someone is in the uterus. Obesity is the root cause of many chronic diseases. The best way to tackle the obesity epidemic is to lessen its burden in children. The earlier we intervene in a person's life; the better will be the results, not only for the individual, but for the country as well. Population-based prevention strategies are the best to tackle this epidemic. It seeks to change the social norm by encouraging an increase in healthy behaviour and a reduction in health risk. They involve shifting the responsibility of tackling health risks from the individual to governments and health ministries.

Key words: Children, India, metabolic syndrome, obesity

\section{INTRODUCTION}

Overweight and obesity are defined as, "abnormal or excessive fat accumulation that presents a risk to health". ${ }^{[1]}$ Obesity has reached epidemic proportions globally, with approximately 1.4 billion adults overweight - at least 300 million of them clinically obese - and is a major contributor to the global burden of chronic disease and disability. ${ }^{[2]}$ Often coexisting in developing countries with under-nutrition, obesity is a complex condition, with serious social and psychological dimensions, affecting virtually all ages and socioeconomic groups.

Obesity is expensive; it may cost two to seven percent of the total health care costs in several developed countries. ${ }^{[3]}$ The true costs are undoubtedly much greater, as not all obesity-related conditions are included in the calculations.

The fundamental causes behind the rising levels of childhood obesity are a shift in diet toward increased intake of energy-dense foods that are high in fat and sugars, but low in vitamins, minerals, and other healthy micronutrients, and a trend toward decreased levels of physical activity. Frequency of eating in restaurants, television viewing hours, hours of physical inactivity, parental overweight, and low maternal education level, are found to be significantly associated with childhood obesity. ${ }^{[4]}$

India, like many low- and middle-income countries, is now facing a 'double burden' of disease: As they continue to struggle with the problems of infectious diseases and under-nutrition; and at the same time they are experiencing a rapid increase in the risk factors of non-communicable diseases (NCDs) such as obesity and overweight, particularly in urban settings. ${ }^{[5]}$ It is not uncommon to find under-nutrition and obesity existing side-by-side within the same community and even within the same household, in these settings.

This double burden is caused by inadequate pre-natal, infant, and child nutrition, which is then followed by exposure to high-fat, energy-dense, micronutrient-poor foods, and a lack of physical activity as the child grows older. 


\section{MEASUREMENT OF OVERWEIGHT AND OBESITY}

Obesity can be measured in different ways. The most common method is measuring the weight and relating it to other parameters. We measure overweight and obesity in adults as the Body Mass Index (BMI) also called quetlet index. This is a simple index to classify overweight and obesity in adult populations and individuals. It is measured by dividing the square of the height in meters by the weight in kilograms $\left(\mathrm{kg} / \mathrm{m}^{2}\right)$. The BMI cut-off for different groups of obesity is the same for both males and females, and for all ages of adults. However, it is considered as a rough guide because it may not correspond to the same body fat percentage in different individuals. Other methods of estimating body fat and body fat distribution include measurements of skin-fold thickness and waist circumference, calculation of waist-to-hip circumference ratios, and techniques such as ultrasound (USG), computed tomography (C'T), and magnetic resonance imaging (MRI).

It is difficult to develop one simple index for the measurement of overweight and obesity in children and adolescents, because their bodies undergo a number of physiological changes as they grow. We cannot have the same criteria for both the sexes and for all the children, irrespective of their ages. Age and sex are considered for children for two reasons: The amount of body fat changes with age and the amount of body fat differs between girls and boys. The World Health Organization (WHO) has released Child Growth Standards in April 2006, mentioning the expected anthropometric measurements for children of age $0-5$ years. ${ }^{[6]}$ These standards have been developed after extensive surveys were conducted in different parts of the world. For individuals from 5-19 years, the WHO has developed the Growth Reference Data. It is a reconstruction of the 1977 National Center for Health Statistics (NCHS)/WHO reference, and uses the original NCHS data set, supplemented with data from the WHO Child Growth Standards sample for young children up to the age of five. The BMI ranges for children and teens are defined so that they take into account normal differences in body fat between boys and girls and differences in body fat at various ages. At birth the median BMI is as low as $13 \mathrm{~kg} / \mathrm{m}^{2}$. It increases to $17 \mathrm{~kg} / \mathrm{m}^{2}$ at age one year, decreases to $15.5 \mathrm{~kg} / \mathrm{m}^{2}$ at six years of age, and then increases again to $21 \mathrm{~kg} / \mathrm{m}^{2}$ at age $20 .{ }^{[7]}$ After the BMI is calculated for children and teens, it is plotted on BMI-for-age growth charts (for either girls or boys), to obtain a percentile ranking. The percentile indicates the relative position of the child's BMI among children of the same sex and age. The growth charts show the weight status categories used with children and teens (underweight, healthy weight, at risk of overweight, and overweight).

In 2001, the International Obesity Task Force (IOTF) proposed a new classification system for overweight and obesity in children. The IOTF group combined the childhood and adult definitions of overweight and obesity prevalent then, by taking, at age 18 years, those percentiles that corresponded to the BMIs of 25 and $30 \mathrm{~kg} / \mathrm{m}^{2}$ and using these same percentiles throughout the age range for specifying overweight and obesity in childhood in girls and boys separately. ${ }^{[8]}$ The IOTF chose data from six countries, that is, National Health and Nutrition Examination Survey I data from the United States, UK data, and surveys from The Netherlands, Hong Kong, Singapore, and Brazil. The composite percentile cutoff points chosen from the six datasets are now used in many parts of the world.

\section{BURDEN OF OBESITY IN CHILDREN}

Childhood overweight and obesity is a form of malnutrition. Childhood obesity is on rise and it is one of the most serious public health challenges of the twenty-first century. There is hardly any country where this problem is not present and it is steadily affecting many low- and middle- income countries, particularly in urban settings. The prevalence has increased at an alarming rate. Globally an estimated 170 million children under the age of 18 years are overweight. ${ }^{[9]}$ It has been estimated that in 2010, 43 million children under the age of five years were overweight. ${ }^{[10]}$ More than $75 \%$ of the overweight and obese children live in low- and middle-income countries. IOTF has shown that one in 10 children is overweight, a total of 155 million. ${ }^{[11]}$ Approximately 30-45 million of these 155 million children are classified as obese, accounting for two to three percent of the world's children of age 5-17 years. In some countries, more than 30 percent of the children are obese. The problem is global and increasingly extends into the developing world; for example, in Thailand, the prevalence of obesity in 5-to 12 -year-old children rose from $12.2 \%$ to $15.6 \%$ in just two years. ${ }^{[12]}$

There have been meagre data from India on the prevalence of childhood obesity. A study ${ }^{[13]}$ was conducted to assess the prevalence of obesity and overweight in adolescent public school girls (10-15 years of age) of Chennai in 1981 and 1998. The first part of the study was done in the year 1981 and the prevalence of overweight among children was compared with the second part in 1998. Almost a similar number of children were taken in both years. Overweight and obesity were denoted by BMI above the eighty-fifth and ninety-fifth percentiles, respectively. The prevalence of overweight (9.6 percent in 1981 and 9.7 percent in 1998) and obesity (5.9 percent in 1981 and 6.2 percent in 1998) was comparable in both studies. It was also observed that the BMI for the corresponding age showed an increase from 1981 to 1998. Another study ${ }^{[14]}$ was done on the adolescent children in urban India, to quantify the prevalence of overweight and its risk factors. School students in the age group of 13-18 years were studied. The BMI was measured and data on physical activity, food habits, occupation of parents, and their economic status, birth weight of the children, and age at menarche in girls were obtained with the help of a questionnaire. Age-adjusted prevalence of overweight was $17.8 \%$ for boys and $15.8 \%$ for girls. It increased with age and was higher in lower tertiles of physical activity and in the higher socioeconomic group. Birth weight and current BMI were positively associated. The study highlighted the high prevalence of overweight in adolescent children in urban India. They also concluded that the lifestyle factors influenced the BMI during adolescent age. A study ${ }^{[15]}$ was conducted in Ludhiana to determine the prevalence of obesity in pre-adolescent and adolescent children, using the WHO guidelines ${ }^{[16]}$ for defining obesity and overweight. This cross-sectional study was carried out on 2008 school children aged 9-15 years. Approximately half the subjects belonged to a school attended by children of well-to-do families, while the rest belonged to two schools from the middle and lower socioeconomic background. Weight and height were taken for all children and the BMI calculated. Children whose BMI was 
more than the eighty-fifth percentile for age and sex were defined as overweight. Triceps skin fold thickness (TSFT) was measured for all overweight children and those with a TSFT of more than the ninetieth percentile for age and sex were defined as obese. The overall prevalence of obesity and overweight was 11.1 and $14.2 \%$, respectively. The prevalence of obesity as well as overweight was higher in boys as compared to girls (12.4 vs. $9.9 \%, 15.7$ vs. $12.9 \%)$. Significantly more children from the higher socioeconomic status were obese and overweight than those from the lower socioeconomic status groups. No significant gender difference for obesity prevalence was seen among the children from a less privileged background; however, among children from affluent families, significantly more boys were obese as compared to girls. When around 25 thousand children were followed for three years, the researchers noticed rapid growth and nutritional transitions, characterized by a decline in the underweight population along with escalation of the overweight population. ${ }^{[17]}$ In the National capital of Delhi overweight is increasing at an alarming rate in urban children. It grew from $16 \%$ in 2002 to about $24 \%$ in $2006-2007 . .^{[18]}$

\section{CHILDHOOD OVERWEIGHT AND PROPENSITY TO DEVELOP OBESITY LATER IN LIFE}

An overweight child has high probability of remaining overweight in adolescence also. ${ }^{[19-21]}$ Data from a number of studies provide strong evidence that higher levels of BMI during childhood can predict overweight later in life. This was summarized in a review by Goran. ${ }^{[2]}$ Data from four longitudinal studies were reviewed and showed that the probability of overweight at 35 years of age for children with BMI in the eighty-fifth to ninety-fifth percentiles increased with increasing age. The prediction for adult weight was most accurate for BMI at 18 years of age, with accuracy for BMI decreasing below 13 years of age. Goran concluded that the persistence of pediatric obesity into adulthood increases according to the age at which obesity is initially present.

An emerging area of research is the potential role of intrauterine growth and growth in the first year of life, for predicting the emergence of increased cardiovascular risk and obesity during adulthood. Dietz and Gortmaker ${ }^{[23]}$ reviewed the Dutch Famine Studies. They noted that individuals who were exposed to famine in-utero, in the first trimester of pregnancy were more likely to be overweight at 18 years of age compared to those exposed to famine at other periods during pregnancy. In contrast, individuals exposed to famine late in pregnancy tended to be underweight at 18 years of age. Although low birth weight and low weight gain in the first year of life may contribute to increased risk of hypertension, dyslipidemia, and cardiovascular risk in the adult population, Dietz and Gortmaker conclude that it is unlikely that low birth weight contributes significantly to obesity prevalence in the adult population. In addition, a child who is born overweight ( $>4 \mathrm{Kg}$.) does have a higher risk of being an overweight adult. These authors suggest that $5 \%$ of adult obesity is attributable to individuals born with high birth weights.

Overweight and obese children are likely to stay obese in adulthood and more likely to develop non-communicable diseases like diabetes $^{[24]}$ and cardiovascular diseases at a younger age. This has been proved by many studies, some of these conducted in India. A cohort study was conducted in Delhi by Sachdev, et al. ${ }^{[25]}$ with the objective of finding a relationship between birth size and BMI during childhood, with anthropometric indices of the adult body composition. A population-based cohort of 1526 men and women aged 26 to 32 years, in Delhi, who were measured sequentially from birth until 21 years of age, were followed up. Adult weight, height, skin-fold thicknesses, and waist and hip circumferences were measured. The BMI and indices of adiposity (sum of skin-fold thicknesses), central adiposity (waist - hip ratio), and lean mass (residual values after adjustment of BMI for skin-fold thicknesses and height) were derived. They found out that the birth weight was positively related to the adult lean mass, and in women, to adiposity. THE BMI from birth to age 21 years was increasingly, strongly, and positively correlated with all the outcomes. Higher BMI and greater BMI gain in late childhood and adolescence were associated with increased adult adiposity and central adiposity. They concluded that greater BMI gain in late childhood and adolescence predicts increased adult adiposity.

\section{HEALTH CONSEQUENCES OF OBESITY IN CHILDREN}

Children who are overweight may begin to experience health consequences during their youth as well as put themselves at risk for weight-related health problems later in life. Overweight children and adolescents have been found to have risk factors for cardiovascular disease, including high cholesterol, elevated insulin levels, and elevated blood pressure during childhood. One study ${ }^{[26]}$ has shown that approximately $60 \%$ of overweight children have at least one cardiovascular risk factor, such as, high cholesterol or high blood pressure; in comparison, only $10 \%$ of the children with healthy weight have at least one risk factor. Additionally, 25\% of overweight children have two or more risk factors. Other health consequences include the following potential problems: ${ }^{[27]}$ Type 2 diabetes, Sleep apnea, and Social consequences, including poor self-esteem and social discrimination. Psychiatric morbidities are also more common among obese people. ${ }^{[2]}$ Psychological problems associated with childhood obesity include negative self-esteem, withdrawal from interaction with peers, depression, anxiety, and the feeling of chronic rejection. The overweight and obesity epidemic has increased the prevalence of hypertension and other chronic conditions in children. ${ }^{[29]}$

For most NCDs resulting from obesity, the risks depend partly on the age of onset and on the duration of obesity. Obese children and adolescents suffer from both short-term and long-term health consequences. Childhood obesity is associated with a higher chance of premature death and disability in adulthood. The most significant health consequences of childhood overweight and obesity, that often do not become apparent until adulthood, include: Cardiovascular diseases (mainly heart disease and stroke); diabetes; musculoskeletal disorders, especially osteoarthritis; and certain types of cancer (endometrial, breast, and colon). At least 2.6 million people each year die as a result of being overweight or obese [Table 1]. ${ }^{[30-31]}$ 


\begin{tabular}{ll} 
Table 1: Physical consequences of childhood and \\
adolescent obesity \\
\hline Organ system & Obesity-related disorders \\
\hline Pulmonary & Sleep apnea \\
& Asthma \\
& Pickwickian syndrome \\
Orthopedic & Slipped capital epiphyses \\
& Blount's disease (tibia vara) \\
& Tibial torsion \\
& Flat feet \\
& Ankle sprains \\
& Increased risk of fractures \\
Neurological & Idiopathic intracranial hypertension \\
Gastroenterological & Cholelithiasis \\
& Liver steatosis/non-alcoholic fatty liver \\
Endocrine & Gastroesophageal reflux \\
& Insulin resistance/impaired glucose tolerance \\
& Type 2 diabetes \\
& Menstrual abnormalities \\
& Polycystic ovary syndrome \\
Hypercorticism \\
Cardiovascular & Dyslipidemia \\
Hypertension & Fatty streaks \\
Others & Left ventricular hypertrophy \\
& Systemic inflammation/raised \\
& C-reactive protein \\
\hline
\end{tabular}

\section{CAUSES OF OVERWEIGHT EPIDEMIC}

Like many other diseases, the cause of obesity in an individual is multifactorial. Similarly, the cause of the current epidemic of overweight can be attributed to many factors. The rising epidemic reflects the profound changes in society and in the behavioral patterns of communities over recent decades. Even as genes are important in determining a person's susceptibility to weight gain, energy balance is determined by calorie intake and physical activity. Thus, societal changes and worldwide nutrition transition are driving the obesity epidemic. Economic growth, modernization, urbanization, and globalization of food markets are just some of the other forces thought to underlie the epidemic.

As incomes rise and populations become more urban, diets high in complex carbohydrates give way to more varied diets, with a higher proportion of saturated fats and sugars. At the same time, large shifts toward less physically demanding work have been observed worldwide. Moves toward less physical activity are also found in the increasing use of motor vehicle, technology in the home, and more passive leisure activities.

Causes of obesity in individuals include poor diet and inadequate exercise. Genetic, hormonal, and environmental factors play a significant role, as does one type of adenovirus. A child with one overweight parent has a $40 \%$ chance of being overweight; with two overweight parents, it is $80 \% \cdot{ }^{[32]}$ A number of medications (OCPs, antidepressants, antipsychotic drugs, etc.) can also contribute to weight gain.

\section{OBESOGENIC ENVIRONMENTS}

Obesogens are the external influences that encourage weight gain. ${ }^{[33]}$
School, family customs, and practices have a strong influence on a child's food preferences and activity patterns, and as the child grows older, he or she may experience social pressure from peers to purchase certain foods, or to undertake sedentary activities. Beyond these local influences, food advertising and labeling policies, road transport policies, and a range of other factors also contribute to the list of potential obesogens.

Some environmental factors shown to contribute to childhood obesity include:

\section{Increase in use of motorized transport}

Children today are more likely to be driven to schools and other meeting places rather than walking. This may be due to an increasing number of persons having access to motor vehicles.

\section{Fall in opportunities for recreational physical activity}

Children today have fewer opportunities to be involved in recreational sporting activities. Many schools due to increased emphasis on academics have cut out or drastically reduced sporting programs.

\section{Increased sedentary recreation}

Today the type of play involves less active games usually restricted to indoor activities like board games and computer games. With a lot more children moving to crowded cities many children do not have a ground to play.

\section{Multiple TV channels around the clock}

With the availability of cable, children can sit and watch cartoons all day long, every day.

\section{Greater quantities and a variety of energy dense foods available}

There are a multitude of different candies and sweets, chocolates, cookies, cakes, sodas/soft drinks available today that provide a high level of calories in relation to the overall nutrient needs of the children.

\section{Rising levels of promotion and marketing of energy-dense foods}

A lot of these energy dense foods are marketed directly to children, so children today are more aware of what is available and are able to ask their parents or purchase what they want to eat with pocket money.

\section{MANAGEMENT OF CHILDHOOD OBESITY}

Pediatric overweight intervention requires a combination of family-based and school-based multi-component programs that include the promotion of physical activity, parent training/modeling, behavioral counseling, and nutrition education. Furthermore, although not yet evidence-based, community-based and environmental interventions are recommended as being the most feasible techniques 
to support healthy lifestyles for a great number of children and their families. The American Dietetic Association did a systematic evidence-based analysis ${ }^{[34]}$ of the pediatric overweight literature on intervention programs. The research showed positive effects of two specific kinds of overweight interventions: (a) Multi-component, family-based programs for children between the ages of five and 12 years, and (b) multi-component, school-based programs for adolescents. Multi-component programs include behavioral counseling, promotion of physical activity, parent training/ modeling, dietary counseling, and nutrition education. Analysis of the literature, to date, points to the need for further investigation of promising strategies not yet adequately evaluated. Furthermore, this review highlights the need for research, to develop effective and innovative overweight prevention programs for various sectors of the population, including those of varying ethnicities, young children, and adolescents.

There are various programs, both interventions and preventive, running in different countries, to decrease the impact of the obesity epidemic on children. Centers for Disease Control and Prevention, USA, studied the various programs, to prevent or treat two- to six-year-old overweight children to find out their effectiveness. ${ }^{[35]}$ They studied seven studies and reported that four of the seven studies (two intervention, two prevention) documented significant reductions in weight status or body fat. Among these, three sustained reductions one to two years after program initiation, two actively and one passively involved parents, three included the multicomponent strategies, and all four monitored behavioral changes. Of the three (prevention) studies that did not show reduction in weight or fat status, all performed assessments between four and nine months after program initiation, and one used a multi component strategy. Other significant changes reported were reductions in television viewing, cholesterol, and parental restriction of child feeding. They concluded that multicomponent programs with one- to two-year follow-ups in clinics or child care settings were successful in their impact on weight; they were likely enhanced by parental involvement. Both treatment programs and two of the five prevention programs reduced weight/fat status.

In approaching childhood obesity, we can consider three levels of prevention: Primordial prevention, which aims toward maintaining normal BMI throughout childhood and adolescence; primary prevention, directed toward preventing overweight children (BMI: Eighty-fifth to the ninety-fifth percentiles) from becoming obese; and secondary prevention, to treat obese children (BMI: Ninety-fifth percentile and more), to reduce comorbidities, and to reverse overweight and obesity, if possible. There is a need to balance energy intake with energy output and to introduce activity in place of inactivity. In obesity prevention, an emphasis on vegetable and fruit consumption will be a major step forward in avoiding energy-dense foods.

The obesity epidemic can be tackled at different stages in a human being, right from the pre-conception stage. Components for obesity prevention at different stages of development can be summarized as:

\section{Perinatal}

Supply good prenatal nutrition and health care, avoid excessive maternal weight increase, control diabetes, help mothers lose weight postpartum, and offer nutrition education.

\section{Infancy}

Encourage increased breast feeding and exclusive breast feeding till six months of age, delay introduction of solid foods until after six months of age, provide a balanced diet, avoid excess high-calorie snacks, and follow weight increase closely.

\section{Preschool}

Provide early experiences with foods and flavors, help develop healthy food preferences, encourage appropriate parental feeding practices, monitor rate of weight increase, to prevent early adiposity rebound, and provide the child and parent nutrition education.

\section{Childhood}

Monitor weight increase for height (slow down if excessive), avoid excessive pre-pubertal adiposity, supply nutrition education, and encourage daily physical activity.

\section{Adolescence}

Prevent excess weight increase after growth spurt, maintain healthy nutrition as the next generation of parents, and continue daily physical activity.

For children who are significantly overweight, the goal should be to reduce severity of obesity and to treat, reduce, and eliminate the comorbidities (e.g., hypertension, dyslipidemia, insulin resistance, and type II diabetes). For energy balance, measures are needed for children to lose weight or to slow down the rate of gain, and to grow to their expected heights. This requires some reduction in energy intake and substantial increases in energy expenditure.

\section{REFERENCES}

1. Available from: http://www.who.int/mediacentre/factsheets/fs311/en/index. html. [Last accessed on 2012 Oct 8].

2. Obesity and overweight. World Health Organization 2003. Available from: http://www.who.int/dietphysicalactivity/media/en/gsfs_obesity.pdf. [Last accessed on 2012 Oct 8].

3. Available from: http://www.who.int/dietphysicalactivity/publications/facts/ obesity/en/. [Last accessed on 2012 Oct 8].

4. Jiang J, Rosenqvist $\mathrm{U}$, Wang $\mathrm{H}$, Greiner T, Ma Y, Toschke AM. Risk factors for overweight in 2- to 6-year-old children in Beijing, China. Int J Pediatr Obes 2006;1:103-8.

5. The double burden of malnutrition. Case studies from six developing countries. Food and nutrition paper 84 . Food and agriculture organization of the United Nations Rome; 2006.

6. de Onis M, Onyango AW, Borghi E, Siyam A, Nishida C, Siekmann J. Development of a WHO growth reference for school-aged children and adolescents. Bull World Health Organ 2007;85:660-7.

7. Cole TJ, Bellizzi MC, Flegal KM, Dietz WH. Establishing a standard definition for child overweight and obesity worldwide: International survey. BMJ 2000;320:1240-3.

8. World Health Organization. Obesity. Preventing and Managing the Global Epidemic. Report of a WHO Consultation on Obesity. Geneva, Switzerland: World Health Organization; 1998.

9. Prioritizing areas for action in the field of population-based prevention of childhood obesity. A set of tools for Member States to determine and identify priority areas for action. World Health Organization 2012. Available from: http://www.who.int/dietphysicalactivity/childhood/Childhood_obesity_ modified_4june_web.pdf www.who.int. [Last accessed on 2012 Oct 8].

10. Population-based strategies for prevention of childhood obesity. Report of the WHO Forum and Technical Committee. Geneva: World Health Organization; 2010. 
11. Lobstein T, Baur L, Uauy R. Obesity in children and young people: A crisis in public health. Obes Rev 2004;5:4-104.

12. Al-Hasani S, Zohni K. The overlooked role of obesity in infertility. J Fam Reprod Health 2008;2:115-22.

13. Subramanyam V, Jayashree R, Rafi M. Prevalence of overweight and obesity in affluent adolescent girls in Chennai in 1981 and 1998. Indian Pediatr 2003:40:775-9.

14. Ramachandran A, Snehalatha C, Vinitha R, Thayyil M, Kumar CK, Sheeba $\mathrm{L}$, et al. Prevalence of overweight in urban Indian adolescent school children. Diabetes Res Clin Pract 2002;57:185-90.

15. Chhatwal J, Verma M, Riar SK. Obesity among pre-adolescent and adolescents of a developing country (India). Asia Pac J Clin Nutr 2004;13:231-5.

16. WHO Expert Committee. Physical status: The use and interpretation of anthropometry. Adolescents. WHO Tech Rep Series 1995;854:263-311.

17. Raj M, Sundaram KR, Paul M, Sudhakar A, Kumar RK. Dynamics of growth and weight transitions in a pediatric cohort from India. Nutr J 2009;8:55.

18. Bhardwaj S, Misra A, Khurana L, Gulati S, Shah P, Vikram NK. Childhood obesity in Asian Indians: A burgeoning cause of insulin resistance, diabetes and sub-clinical inflammation. Asia Pac J Clin Nutr 2008;17:172-5.

19. Zack PM, Harlan WR, Leaverton PE, Cornoni-Huntley J. A longitudinal study of body fatness in childhood and adolescence. J Pediatr 1979;95:126-30.

20. Whitaker RC, Wright JA, Pepe MS, Seidel KD, Dietz WH. Predicting obesity in young adulthood from childhood and parental obesity. $\mathrm{N}$ Engl $\mathrm{J}$ Med 1997;37:869-73

21. Ferraro KF, Thorpe RJ Jr, Wilkinson JA. The life course of severe obesity: Does childhood overweight matter? Journal of Gerontology: Social Sciences $\mathrm{Br}$ 2003;58:S110-9.

22. Goran MI. Metabolic precursors and effects of obesity in children: A decade of progress, 1990-1999. Am J Clin Nutr 2001;73:158-71.

23. Dietz WH, Gortmaker SL. Preventing obesity in children and adolescents. Annu Rev Public Health 2001;22:337-53.

24. American Diabetes Association. Type 2 diabetes in children and adolescents. Diabetes Care 2000;23:381-9.

25. Sachdev HS, Fall CH, Osmond C, Lakshmy R, Dey Biswas SK, Leary SD, et al. Anthropometric indicators of body composition in young adults: Relation to size at birth and serial measurements of body mass index in childhood in the New Delhi birth cohort. Am J Clin Nutr 2005;82:456-66.

26. Freedman DS, Dietz WH, Srinivasan SR, Berenson GS. The relation of overweight to cardiovascular risk factors among children and adolescents: The Bogalusa Heart Study. Pediatrics 1999;103:1175-82.

27. Must A, Anderson SE. Effects of obesity on morbidity in children and adolescents. Nutr Clin Care 2003;6:4-12.

28. Carpenter KM, Hasin DS, Allison DB, Faith MS. Relationships between obesity and DSM-IV major depressive disorder, suicide ideation, and suicide attempts: Results from a general population survey. Am J Publ Health 2000;90:251-7.

29. Muntner P, He J, Cutler JA, WIldman RP, Whelton PK. Trends in blood pressure among children and adolescents. JAMA 2004;291:2107-13.

30. Preventing chronic diseases: A vital investment. WHO Global Report; 2005.

31. International Obesity Task Force (2004) Obesity in children and young people, a crisis in public health. Available from: http://www.iotf.org. [Last accessed on 2012 Oct 6].

32. Donohoe M. Weighty matters: Public health aspects of the obesity epidemic Part I - Causes and health and economic consequences of obesity. Available from: http://www.medscape.com/viewarticle/566056. [Last accessed on 2012 Oct 6].

33. Lobstein T. Can we prevent child obesity? Childhood Obesity Working Group. International Association for the Study of Obesity. Available from: http://www.bvsde.paho.org/bvsacd/cd66/TimLobstein.pdf. [Last accessed on 2012 Oct 6].

34. American Dietetic Association (ADA). Position of the American Dietetic Association: Individual-, family-, school-, and community-based interventions for pediatric overweight. J Am Diet Assoc 2006;106:925-45.

35. Bluford DA, Sherry B, Scanlon KS. Interventions to prevent or treat obesity in preschool children: A review of evaluated programs. Obesity 2007;15:1356-72.

How to cite this article: Singh R. Childhood obesity: An epidemic in waiting? Int J Med Public Health 2013;3:2-7.

Source of Support: Nil, Conflict of Interest: None declared. 